\title{
Unidirectional opioid-cannabinoid cross-tolerance in the modulation of social play behavior in rats
}

\author{
Sara Schiavi ${ }^{1} \cdot$ Antonia Manduca $^{1} \cdot$ Marco Segatto $^{1} \cdot$ Patrizia Campolongo $^{2} \cdot$ Valentina Pallottini $^{1}$ • \\ Louk J. M. J. Vanderschuren ${ }^{3} \cdot$ Viviana Trezza $^{1}$
}

Received: 16 November 2018 / Accepted: 10 March 2019 / Published online: 22 March 2019

(C) Springer-Verlag GmbH Germany, part of Springer Nature 2019

\begin{abstract}
Rationale The endocannabinoid and the endogenous opioid systems interact in the modulation of social play behavior, a highly rewarding social activity abundantly expressed in young mammals. Prolonged exposure to opioid or cannabinoid receptor agonists induces cross-tolerance or cross-sensitization to their acute behavioral effects.

Objectives and methods Behavioral and biochemical experiments were performed to investigate whether cross-tolerance or cross-sensitization occurs to the play-enhancing effects of cannabinoid and opioid drugs on social play behavior, and the possible brain substrate involved.

Results The play-enhancing effects induced by systemic administration of JZL184, which inhibits the hydrolysis of the endocannabinoid 2-AG, were suppressed in animals repeatedly pretreated with the opioid receptor agonist morphine. Conversely, acute morphine administration increased social play in rats pretreated with vehicle or with either JZL184 or the cannabinoid agonist WIN55,212-2. Acute administration of JZL184 increased the activation of both CB1 receptors and their effector Akt in the nucleus accumbens and prefrontal cortex, brain regions important for the expression of social play. These effects were absent in animals pretreated with morphine. Furthermore, only animals repeatedly treated with morphine and acutely administered with JZL184 showed reduced activation of CB1 receptors and Akt in the amygdala.

Conclusions The present study demonstrates a dynamic opioid-cannabinoid interaction in the modulation of social play behavior, occurring in limbic brain areas strongly implicated in social play behavior. A better understanding of opioid-cannabinoid interactions in social play contributes to clarify neurobiological aspects of social behavior at young age, which may provide new therapeutic targets for social dysfunctions.
\end{abstract}

Keywords Cannabinoid $\cdot$ Opioid $\cdot$ Social play behavior $\cdot$ Rats $\cdot 2$-AG $\cdot$ Morphine

Sara Schiavi and Antonia Manduca contributed equally to this work.

Electronic supplementary material The online version of this article (https://doi.org/10.1007/s00213-019-05226-y) contains supplementary material, which is available to authorized users.

Viviana Trezza

viviana.trezza@uniroma3.it

1 Department of Science, Section of Biomedical Sciences and Technologies, University "Roma Tre", Viale G. Marconi 446, 00146 Rome, Italy

2 Department of Physiology and Pharmacology "V. Erspamer", Sapienza University of Rome, Rome, Italy

3 Department of Animals in Science and Society, Division of Behavioural Neuroscience, Faculty of Veterinary Medicine, Utrecht University, Utrecht, The Netherlands

\section{Introduction}

In humans as in animals, positive social interactions are important for well-being, healthy development, and establishment and maintenance of adequate social structures. One of the most pleasurable social activities displayed in youth by mammals is social play behavior. Social play is important for the development of social, cognitive, and emotional competences, and it is disrupted in pediatric psychiatric disorders (Vanderschuren et al. 2016). In rodents, social play behavior peaks after weaning (postnatal day (PND) 21) until midadolescence (PND 35-46), equivalent to childhood to early/ mid adolescence in humans (McCutcheon and Marinelli 2009; Panksepp 1981; Spear 2000).

Operant and classical conditioning studies in rodents have shown that social play is a highly rewarding activity 
(Vanderschuren et al. 2016). Accordingly, pharmacological experiments have demonstrated that social play behavior is modulated by neurotransmitters involved in reward and motivation, such as endocannabinoids and endogenous opioids (Trezza et al. 2010, 2011b; Vanderschuren et al. 2016).

The endocannabinoid and the endogenous opioid systems have functional similarities in the sense that they share neuroanatomical, neurochemical, and pharmacological characteristics (Befort 2015; Parolaro et al. 2010; Wenzel and Cheer 2018).

The endocannabinoid system is abundant in brain regions involved in reward processes. It consists of lipid signaling messengers (endocannabinoids, mainly anandamide and 2arachidonoylglycerol (2-AG)) which are synthesized following neuronal depolarization (Mechoulam et al. 2014; Piomelli 2003). Endocannabinoids are mostly synthesized postsynaptically and act as retrograde messengers regulating the release of a variety of neurotransmitters at the presynaptic level (Di Marzo 2006; Di Marzo et al. 2004; Piomelli 2003). When released from the postsynaptic neuron, endocannabinoids bind to Gi/Go-coupled cannabinoid receptors (CB1 and CB2, mainly expressed in the brain and periphery, respectively). Their actions end with the degradation by fatty acid amide hydrolase (FAAH) and monoacylglycerol lipase (MAGL), hydrolytic enzymes for anandamide and 2AG, respectively (Mechoulam et al. 2014; Piomelli 2003).

Similarly to endocannabinoids, endogenous opioid peptides such as enkephalins, endorphins, and dynorphins activate $\mathrm{Gi} / \mathrm{Go}$ protein-coupled metabotropic receptors (mu, delta, and kappa) (Filizola and Devi 2013; Kieffer 1995) that are highly expressed in brain areas that mediate reward and motivation (Erbs et al. 2015; Koob and Volkow 2010; Le Merrer et al. 2009; Vanderschuren et al. 2016).

Although different neurotransmitter systems are involved in social play behavior (Siviy and Panksepp 2011; Vanderschuren et al. 1997), the endocannabinoid and endogenous opioid systems play a key role in the modulation of the rewarding properties of social play, and they have been shown to closely interact in the regulation of this behavior (Vanderschuren et al. 2016). Endocannabinoids are released during social play in the nucleus accumbens (NAc) and amygdala (Trezza et al. 2012), and drugs that increase the levels of the endocannabinoids anandamide and 2-AG by inhibiting their hydrolysis enhance social play acting within these brain areas (Manduca et al. 2016; Trezza et al. 2012). The prefrontal cortex also has a role in cannabinoid modulation of social play behavior (Schneider and Koch 2005). Likewise, changes in brain opioid activity occur during social play in different brain areas, including the NAc (Vanderschuren et al. 1995a) and both systemic (Vanderschuren et al. 1995b) and intra-NAc (Trezza et al. 2011a) administration of opioid receptor agonists and antagonists increase and suppress social play, respectively, through interaction with mu-opioid receptors.
Noteworthy, reciprocal interactions between the endocannabinoid and the opioid systems are involved not only in drug (Befort 2015; Fattore et al. 2005) and food (Solinas and Goldberg 2005) rewards but also in social play reward (Manduca et al. 2016; Trezza and Vanderschuren 2008; Vanderschuren et al. 2016).

Previous studies have demonstrated that prolonged exposure to either opioid or cannabinoid receptor agonists results in cross-tolerance or cross-sensitization to most of their acute behavioral effects (Maldonado 2002; Robledo et al. 2008). Given the previously reported opioid-cannabinoid interaction in the modulation of social play behavior (Manduca et al. 2016; Trezza et al. 2010; Vanderschuren et al. 2016), the aim of the present study was to investigate whether crosstolerance or cross-sensitization would occur to the playenhancing effects of cannabinoid and opioid drugs. To address this aim, we used two play-enhancing drugs whose effects on social play have been previously well characterized: the 2-AG hydrolysis inhibitor JZL184 (Manduca et al. 2016) and the opioid receptor agonist morphine (Vanderschuren et al. 1995a, b). JZL184 is a high selective 2-AG hydrolysis inhibitor that increases brain 2-AG level when administered systemically (Fowler 2012; Long et al. 2009). We have recently shown that the increase in social play induced by systemic administration of JZL184 requires the activation of both opioid and cannabinoid receptors (Manduca et al. 2016). However, since JZL184 is an indirect cannabinoid agonist (i.e., it increases $2-\mathrm{AG}$ levels, but it does not directly bind cannabinoid receptors), we performed also an additional experiment in which we tested whether the play-enhancing effects of morphine were maintained, or not, when rats were repeatedly pretreated with the $\mathrm{CB} 1$ cannabinoid receptor agonist WIN 55,212-2.

There is experimental evidence that CB1 receptor activation by endogenous and/or exogenous cannabinoids leads to the induction of signaling cascades culminating in Akt protein activation (Bouaboula et al. 1995; Gomez del Pulgar et al. 2000; Ozaita et al. 2007; Wartmann et al. 1995). Thus, the evaluation of Akt phosphorylation is a reliable readout to assess CB1 cannabinoid receptor activation. For this reason, we measured the expression of both phosphorylated and total CB1 receptor protein and its effector Akt in the amygdala, NAc and prefrontal cortex, key brain regions implicated in social play behavior (Vanderschuren et al. 2016).

\section{Experimental procedures}

\section{Animals}

Male Wistar rats (Charles River Laboratories, Italy) arrived in the animal facility at 21 days of age, and they were housed in groups of five in Macrolon cages $(43 \times 26 \times 20 \mathrm{~cm})$ under 
controlled conditions (temperature $21 \pm 1{ }^{\circ} \mathrm{C}, 60 \pm 10 \%$ relative humidity and $12 / 12 \mathrm{~h}$ light cycle with lights on at 07:00 a.m.). Food and water were available ad libitum. Animals were experimentally naive and were used only once. Sample size $(n)$ is indicated in the figure legends. The experiments were approved by the Italian Ministry of Health (Rome, Italy) and performed in agreement with the ARRIVE (Animals in Research: Reporting In Vivo Experiments) (Kilkenny et al. 2010) guidelines, with the guidelines released by the Italian Ministry of Health (D.L. 26/14) and the European Community Directive 2010/63/EU.

\section{Drugs}

The monoacylglycerol lipase (MAGL) inhibitor JZL184 [4-[Bis(1,3-benzodioxol-5-yl)hydroxymethyl]-1piperidinecarboxylic acid 4-nitrophenyl ester] (National Institute of Mental Health's (NIMH) Chemical Synthesis and Drug Supply Program, USA) and the CB1 cannabinoid receptor agonist WIN 55,212-2 (WIN) (TOCRIS, UK) were dissolved in 5\% Tween $80 / 5 \%$ polyethylene glycol/saline. The opioid receptor agonist morphine (SALARS, Italy) was dissolved in saline. JZL184 (1 mg/kg) and WIN $(0.3 \mathrm{mg} / \mathrm{kg})$ were given intraperitoneally (i.p.), while morphine $(1 \mathrm{mg} / \mathrm{kg}$ ) was administered subcutaneously (s.c.). These doses of JZL184 and morphine are known to increase social play behavior in rats following acute systemic administration (Manduca et al. 2016; Trezza and Vanderschuren 2008). As vehicle for JZL184 and WIN (VEH), we used a mixture of 5\% Tween $80,5 \%$ polyethylene glycol and $90 \%$ saline, while the vehicle for morphine was saline solution (SAL). Solutions were freshly prepared on the day of the experiment and were administered in a volume of $2 \mathrm{ml} / \mathrm{kg}$.

\section{Behavioral experiments}

\section{Social play behavior}

Social play was assessed as previously described (Manduca et al. 2016). The experiments were performed in a sound attenuated chamber under dim light conditions. The testing arena consisted of a Plexiglas cage $(40 \times 40 \times 60 \mathrm{~cm})$ with approximately $2 \mathrm{~cm}$ of wood shavings covering the floor.

At 26-28 days of age, rats were individually habituated to the test cage for $10 \mathrm{~min}$ on 2 days prior to testing. On the test day, the animals were socially isolated for $3.5 \mathrm{~h}$ before testing. This isolation period has been shown to induce a halfmaximal increase in the amount of social play behavior (Niesink and van Ree 1982). At the appropriate time before testing, pairs of animals were treated with drugs or vehicle. In all experiments, both animals of a pair received the same drug treatment. The test consisted of placing two animals into the test cage for $15 \mathrm{~min}$. The animals of each pair did not differ more than $10 \mathrm{~g}$ in body weight and had no known previous common social experience (i.e., they were not cage mates).

Behavior was assessed per pair of animals using the Observer 3.0 software (Noldus Information Technology BV, Wageningen, The Netherlands). In rats, a bout of social play behavior starts with one rat soliciting ("pouncing") another animal, by attempting to nose or rub the nape of its neck. The animal that is pounced upon can respond in different ways. If the animal that is pounced upon fully rotates to its dorsal surface, pinning is the result, i.e., one animal lying with its dorsal surface on the floor with the other animal standing over it. From this position, the supine animal can initiate another play bout, by trying to gain access to the other animal's neck. Thus, during social play, pouncing is considered an index of play solicitation, while pinning can be regarded as the terminal component of a single play bout as well as a releaser of a prolonged play bout (Pellis and Pellis 1987). Pinning and pouncing events can be easily quantified, and they are considered to be the most characteristic parameters of social play behavior in rats (Panksepp and Beatty, 1980). During the social encounter, animals may also display social behaviors not directly associated with play, such as sniffing or grooming the partner's body. A pair of rats was considered as one experimental unit. The following parameters were therefore scored per pair of animals:

Social behaviors directly related to play:

- Number of pinning events during the 15-min test session.

- Number of pouncing events during the 15-min test session.

Social behaviors unrelated to play:

- Time spent in social exploration: the total amount of time (s) spent in non-playful forms of social interaction (i.e., one animal sniffing or grooming any part of the partner's body).

First, we investigated whether cross-tolerance would occur to the effects of JZL184 and morphine on social play after repeated treatment with either compounds. To this aim, three experiments were performed (Fig. 1). In experiment 1, animals were pretreated with either morphine (MOR, $1.0 \mathrm{mg} / \mathrm{kg}$, s.c.) or saline solution (SAL) for five consecutive days (postnatal days 23-27). On day 28,1 day after the last pretreatment injection, animals were isolated for $3.5 \mathrm{~h}$. Next, half of both pretreatment groups (MOR or SAL) was treated with either JZL184 (1 mg/kg, i.p., $2 \mathrm{~h}$ before testing) or its vehicle (VEH), and tested for social play behavior as described above. In experiment 2, animals were pretreated with JZL184 (JZL, $1.0 \mathrm{mg} / \mathrm{kg}$, i.p.) or its vehicle (VEH) for five consecutive days (postnatal days 23-27). On day 28, animals were isolated for 3.5 h. Next, half of both pretreatment groups (JZL or VEH) 
Timeline of the experiments

Behavioral experiment 1

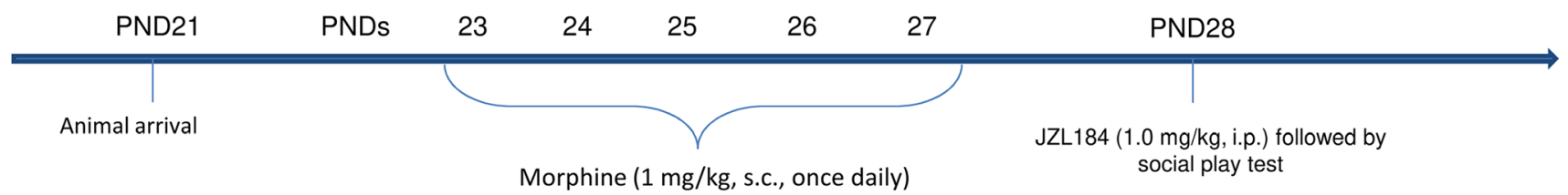

Behavioral experiment 2
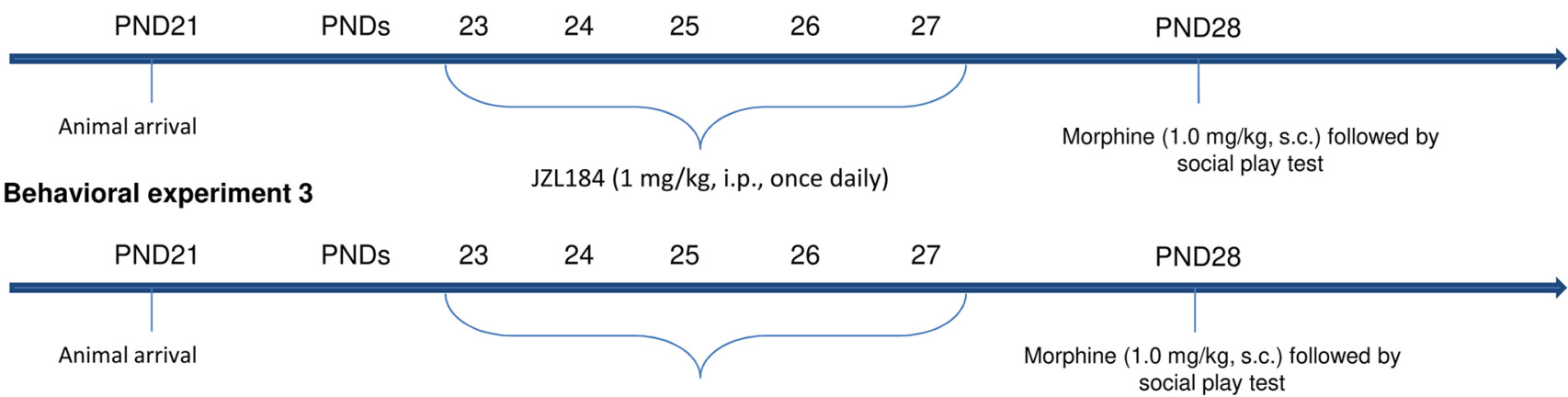

Biochemical experiments

WIN 55,212-2 (0.3 mg/kg, i.p., once daily)

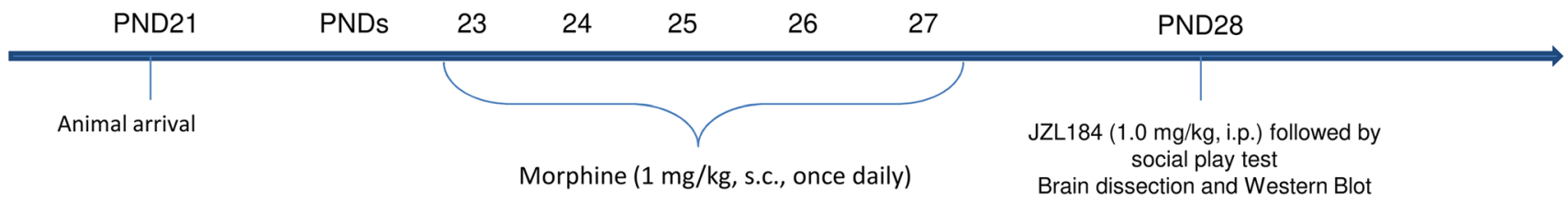

Fig. 1 Timeline of the experiments

was treated with either morphine (MOR, $1 \mathrm{mg} / \mathrm{kg}$, s.c., $1 \mathrm{~h}$ before testing) or saline (SAL), and tested for social play behavior as described above. In experiment 3, animals were pretreated with WIN55,212-2 (WIN, $0.3 \mathrm{mg} / \mathrm{kg}$, i.p.) or its vehicle (VEH) for five consecutive days (postnatal days 2327). On day 28 , animals were isolated for $3.5 \mathrm{~h}$. Next, half of both pretreatment groups (WIN55,212-2 or VEH) was treated with either morphine (MOR, $1 \mathrm{mg} / \mathrm{kg}$, s.c., $1 \mathrm{~h}$ before testing) or saline (SAL), and tested for social play behavior as described above.

\section{Western blot analysis of phosphorylated and total CB1 cannabinoid receptor}

\section{Lysate preparation from brain tissue}

Immediately after testing for social play behavior, rats repeatedly treated with morphine (or saline solution) and acutely treated with JZL184 (or its vehicle) were rapidly decapitated and their brains quickly removed and rinsed in ice-cold distilled water for $10 \mathrm{~s}$. The brains were then cut into coronal slices on a cold plate, and the amygdala,
NAc, and prefrontal cortex were dissected by hand under microscopic control within 2 min (Gray et al. 2015; Hill et al. 2010). Tissues were stored at $-80{ }^{\circ} \mathrm{C}$ until use. Lysates from brain regions were prepared accordingly to the previously used protocol (Segatto et al. 2014). Briefly, brain regions were lysed by sonication in a sample buffer (0.125 M TrisHCL pH 6.8, 10\% SDS, Protease and Phosphatase Inhibitor Cocktails, Sigma, Italy). The lysate was then centrifuged at $13.000 \mathrm{rpm}$ for $10 \mathrm{~min}$ to remove cell/tissue debris. Protein concentration was estimated by the method of Lowry et al. (1951). Samples were subsequently boiled for $3 \mathrm{~min}$ before loading to the SDS-PAGE for Western blotting analysis.

\section{Western blotting analysis}

Western blot experiments were performed as previously described (Segatto et al. 2014) Briefly, proteins (30 $\mu \mathrm{g})$ from amygdala, prefrontal cortex, and NAc lysates were resolved by $10 \%$ (for p-Akt, Santa Cruz sc-7985-R; t-Akt, Santa Cruz sc-8312; p-CB1 Santa Cruz (ser-316) sc17555; t-CB1 (k-15) sc-10068 Santa Cruz) SDS-PAGE 
at $40 \mathrm{~mA}$ (constant current) for $60 \mathrm{~min}$. Proteins were then transferred onto nitrocellulose membrane by using Trans-Blot Turbo Transfer System (Bio-Rad Laboratories, Milan, Italy). The nitrocellulose membrane was blocked at room temperature with $5 \%$ fat-free milk in Tris-buffered saline $(0.138 \mathrm{M} \mathrm{NaCl}, 0.027 \mathrm{M} \mathrm{KCl}$, $0.025 \mathrm{M}$ Tris- $\mathrm{HCl}$, and $0.05 \%$ Tween-20, $\mathrm{pH}$ 6.8), and probed at $4{ }^{\circ} \mathrm{C}$ overnight with primary antibodies followed by incubation for $1 \mathrm{~h}$ with horseradish peroxidaseconjugated secondary IgG antibodies (Bio-Rad Laboratories, Milan, Italy). Subsequently, the nitrocellulose membrane was incubated with anti-tubulin ( $\alpha$-tubulin DM-1A; Sigma, Italy) antibody. Bound antibodies to proteins onto nitrocellulose were visualized by using enhanced chemoluminescence detection (GE Healthcare) and exposure to Amersham Hyperfilm ECL (GE Healthcare). Western blotting images were analyzed by ImageJ (National Institutes of Health, Bethesda, MD, USA) software for Windows. The visualization of the housekeeping protein $\alpha$-tubulin served as loading control. Thus, each reported value was obtained from the ratio between arbitrary units derived by the protein band and the respective $\alpha$-tubulin.

\section{Statistical analysis}

Data are expressed as mean \pm SEM, and statistical significance was set at $p<0.05$. To assess the effects of treatments on behavioral parameters, data were analyzed using two-way ANOVA (with pretreatment and acute treatment as independent factors), followed by Student-Newman-Keuls post hoc tests where appropriate. To assess the effects of treatments on biochemical parameters, data were analyzed using the nonparametric Kruskall-Wallis test followed by Mann-Whitney $U$ test. To check the normality of the behavioral data, the Shapiro-Wilk test was performed (Shapiro and Wilk 1965).

\section{Results}

\section{Behavioral experiments}

Repeated administration of the opioid receptor agonist morphine causes cross-tolerance to the play-enhancing effects of the 2-AG hydrolysis inhibitor JZL184

To evaluate whether cross-tolerance or sensitization occurs to the play-enhancing effects of JZL184 on social play behavior after repeated treatment with morphine, animals were treated with morphine ( $1 \mathrm{mg} / \mathrm{kg}$, s.c.) or saline once daily for five consecutive days. On the sixth day, the animals were tested after treatment with either a dose of the MAGL inhibitor JZL184 $(1.0 \mathrm{mg} / \mathrm{kg}$, i.p.) that is known to increase social play behavior (Manduca et al. 2016) or its vehicle.

Systemic administration of JZL184 increased social play in saline-pretreated rats but not in morphine-pretreated rats (pinning: $F_{\text {(acute) } 1,33}=4.160, p=0.049 ; F_{\text {(repeated) } 1,33}=3.272, p=$ $0.080 ; F_{\text {(acute } \times \text { repeated) } 1,33}=2.170, p=0.150$; pouncing: $F_{\text {(acute) } 1,33}=6.039, p=0.019 ; F_{\text {(repeated) } 1,33}=2.040, p=$ $0.163 ; F_{\text {(acute } \times \text { repeated) } 1,33}=$ n.s., $p=0.328$ ). Post hoc analyses revealed that JZL184 increased the number of pinning (Fig. 2a) and pouncing (Fig. 2b) in animals pretreated with saline but not with morphine, indicating that tolerance to the effect of JZL184 had occurred after repeated stimulation of mu-opioid receptors. Social exploration was not affected by either treatment $\left(F_{\text {(acute) } 1,33}=\right.$ n.s., $p=0.801 ; F_{\text {(repeated) } 1,33}=$ $1.716, p=0.199 ; F_{\text {(acute } \times \text { repeated) } 1,33}=$ n.s., $p=0.637$, Fig. $\left.2 \mathrm{c}\right)$.

\section{Repeated administration of either the 2-AG hydrolysis inhibitor JZL184 or the CB1 cannabinoid receptor agonist WIN does not interfere with the play-enhancing effects of morphine}

To evaluate whether cross-tolerance or sensitization occurs to the play-enhancing effects of morphine after repeated

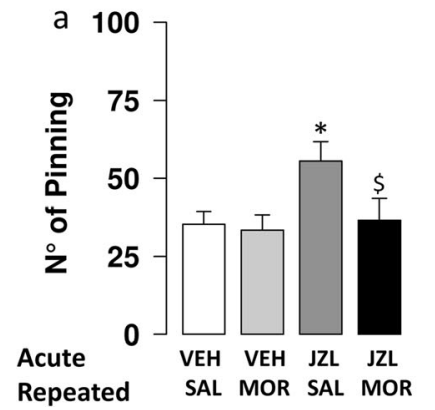

Fig. 2 Repeated administration of the opioid receptor agonist morphine causes cross-tolerance to the play-enhancing effects of the 2-AG hydrolysis inhibitor JZL184. Systemic administration of the 2-AG hydrolysis inhibitor JZL184 (JZL; $1 \mathrm{mg} / \mathrm{kg}$, i.p.) increased the number of pinning (a) and pouncing (b) in animals repeatedly treated with saline (SAL) but not
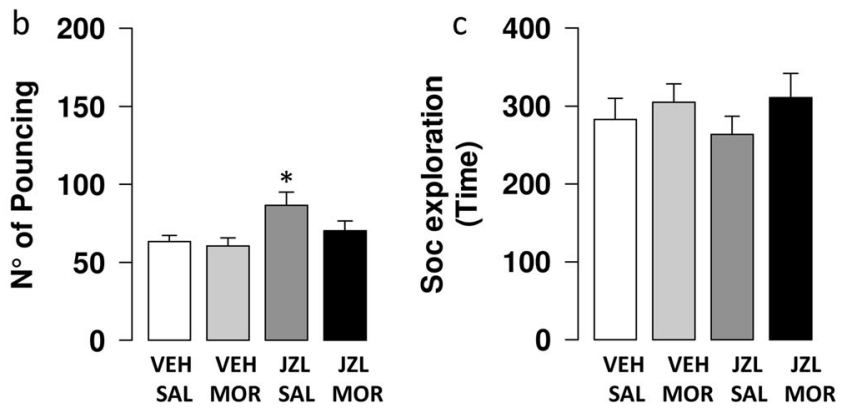

in animals pretreated with morphine (MOR; $1.0 \mathrm{mg} / \mathrm{kg}$, s.c.). Social exploration was not affected by either treatment (c) $(n=$ VEH-SAL 10, $n=$ VEH-MOR $8, n=$ JZL-SAL $11, n=$ JZL-MOR 8 ). Data represent mean values \pm SEM; $* p<0.05$ vs VEH-SAL group, $\$ p<0.05$ vs JZL-SAL group (Student-Newman-Keuls post hoc test) 
treatment with the 2-AG hydrolysis inhibitor JZL184, animals were treated with JZL184 (1 mg/kg, i.p.) or its vehicle once daily for five consecutive days. On the sixth day, the animals were tested after treatment with a dose of the opioid receptor agonist morphine $(1.0 \mathrm{mg} / \mathrm{kg}$, s.c.) that is known to increase social play (Trezza and Vanderschuren 2008).

Acute administration of morphine markedly increased social play in both rats repeatedly pretreated with vehicle or with JZL1 84 (pinning, $F_{\text {(acute) } 1,24}=23.87, p<0.001$; $F_{\text {(repeated)1,24 }}=$ n.s., $p=0.857 ; F_{\text {(acute } \times \text { repeated)1,24 }}=$ n.s., $p=$ 0.983 ; pouncing, $F_{\text {(acute) } 1,24}=26.50, p<0.001$; $F_{\text {(repeated)1,24 }}=$ n.s., $p=0.765 ; F_{\text {(acute } \times \text { repeated) } 1,24}=$ n.s., $p=$ 0.333 ). Post hoc analysis revealed that morphine increased the number of pinning (Fig. 3a) and pouncing (Fig. 3b) regardless of whether the animals were repeatedly pretreated with vehicle or JZL184, indicating that cross-tolerance to the playenhancing effects of morphine after repeated administration of the 2-AG hydrolysis inhibitor JZL184 had not occurred. Social exploration was not affected in any treatment group $\left(F_{\text {(acute) } 1,24}=2.044, p=0.166 ; F_{\text {(repeated) } 1,24}=1.883, p=\right.$ $0.183 ; F_{\text {(acute } \times \text { repeated)1,24 }}=$ n.s., $p=0.369$, Fig. 3 c).

To exclude the possibility that JZL184 failed to induce cross-tolerance (or sensitization) to the play-enhancing effects of acute morphine administration due to its pharmacological profile (i.e., JZL184 is a 2-AG hydrolysis inhibitor rather than a direct $\mathrm{CB} 1$ receptor agonist), an additional experiment was performed: animals were repeatedly treated with the CB1 cannabinoid receptor agonist WIN55,212-2 (WIN, $0.3 \mathrm{mg} / \mathrm{kg}$, i.p.) or its vehicle once daily for five consecutive days. On the sixth day, the animals were tested after treatment with a dose of the opioid receptor agonist morphine $(1.0 \mathrm{mg} / \mathrm{kg}$, s.c. $)$ that is known to increase social play (Trezza and Vanderschuren 2008).

Acute administration of morphine markedly increased social play in rats repeatedly pretreated with vehicle or with WIN (pinning, $F_{\text {(acute)1,28 }}=80.74, p<0.001 ; F_{\text {(repeated)1,28 }}=$ n.s., $p=0.755 ; F_{\text {(acute } \times \text { repeated) } 1,28}=$ n.s., $p=0.734$; pouncing, $F_{\text {(acute) } 1,28}=90.31, p<0.001 ; F_{\text {(repeated)1,28 }}=$ n.s., $p=0.66$;
$F_{\text {(acute } \times \text { repeated)1,28 }}=1.054, p=0.313$ ). Post hoc analysis revealed that morphine increased the number of pinning (Fig. 4a) and pouncing (Fig. 4b) regardless of whether the animals were repeatedly pretreated with vehicle or WIN, indicating that cross-tolerance to the play-enhancing effects of morphine after repeated administration of the CB1 cannabinoid receptor agonist WIN had not occurred. Social exploration was not affected in any treatment group $\left(F_{\text {(acute)1,28 }}=\right.$ n.s., $p=0.731 ; F_{\text {(repeated) } 1,28}=$ n.s., $p=0.375 ; F_{(\text {acute } \times \text { repeated) } 1,28}=$ n.s., $p=0.472$, Fig. 4 c). These results confirm that unidirectional opioid-cannabinoid cross-tolerance exists in the modulation of social play behavior in rats.

\section{Biochemical experiments}

Since the behavioral experiments showed that repeated administration of the opioid receptor agonist morphine caused cross-tolerance to the play-enhancing effects induced by acute administration of the 2-AG hydrolysis inhibitor JZL184, we measured CB1 cannabinoid receptor and p-Akt phosphorylation in the amygdala, NAc, and prefrontal cortex of rats acutely treated with JZL184 after repeated treatment with morphine, since these brain regions have a key role in the modulation of social play behavior (Vanderschuren et al. 2016).

\section{CB1 cannabinoid receptor and p-Akt phosphorylation in the amygdala of rats acutely treated with JZL184 after repeated treatment with morphine}

Animals treated with morphine for 5 days, followed by acute treatment with JZL184 before testing showed a reduction in the ratio between phosphorylated and total $\mathrm{CB} 1$ receptor protein compared to all the other experimental groups $(p<0.01$, Mann-Whitney $U$ test for JZL-MOR vs VEH-SAL, VEHMOR, and JZL-SAL, Fig. 5a). Likewise, in animals injected for 5 days with morphine and treated acutely with JZL184 before testing a reduction in the ratio between phosphorylated and total Akt protein when compared to all the other
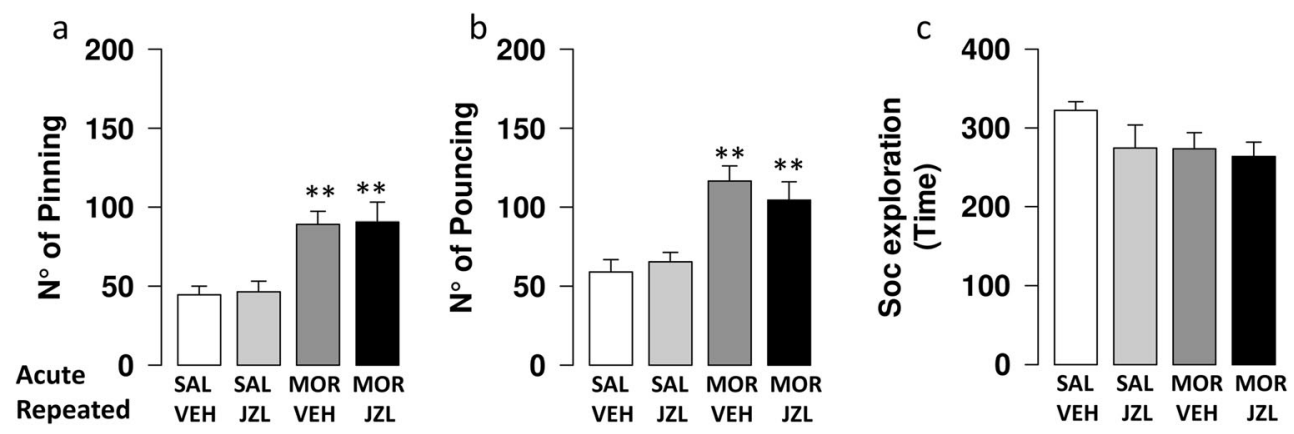

Fig. 3 Repeated administration of the 2-AG hydrolysis inhibitor JZL184 does not cause cross-tolerance to the play-enhancing effects of morphine. Systemic administration of morphine (MOR; $1 \mathrm{mg} / \mathrm{kg}$ s.c.) before testing increased the number of pinning (a) and pouncing (b) regardless the animals were repeatedly treated with vehicle (VEH) or JZL184 (JZL;
$1 \mathrm{mg} / \mathrm{kg}$, i.p.). Social exploration was not affected by either treatment (c) $(n=\mathrm{SAL}-\mathrm{VEH} 7, n=\mathrm{SAL}-\mathrm{JZL} 7, n=\mathrm{MOR}-\mathrm{VEH}$ 6, $n=$ MOR-JZL 8). Data represent mean values $\pm \mathrm{SEM} ; * *<<0.01$ vs SAL-VEH group (Student-Newman-Keuls post hoc test)) 


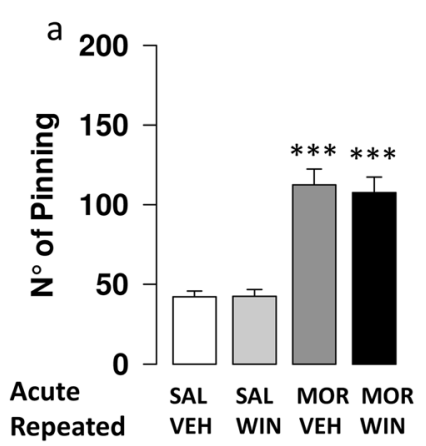

Fig. 4 Repeated administration of the CB1 cannabinoid receptor agonist WIN 55,212-2 does not cause cross-tolerance to the play-enhancing effects of morphine. Systemic administration of morphine (MOR; $1 \mathrm{mg} / \mathrm{kg}$ s.c.) before testing increased the number of pinning (a) and pouncing (b) regardless the animals were repeatedly treated with WIN

experimental groups was found $(p<0.05$, Mann-Whitney $U$ test for JZL-MOR vs VEH-SAL, VEH-MOR, and JZL-SAL, Fig. $5 b)$. These results indicate that the 2-AG hydrolysis inhibitor JZL184 reduced the activation of amygdala CB1 receptors only in animals pretreated with morphine.

\section{CB1 cannabinoid receptor and p-Akt phosphorylation} in the NAC of rats acutely treated with JZL184 after repeated pretreatment with morphine

The acute administration of JZL184 increased the ratio between phosphorylated and total CB1 receptors in the NAc, but this effect was absent in rats pretreated with morphine $(p<0.05$, Mann-Whitney $U$ test for JZL-MOR vs JZL-SAL

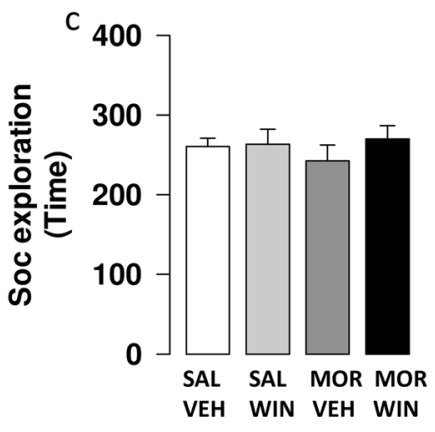

55,212-2 (WIN; $0.3 \mathrm{mg} / \mathrm{kg}$, i.p.) or its vehicle (VEH). Social exploration was not affected by either treatment (c) $(n=\mathrm{SAL}-\mathrm{VEH} 8, n=\mathrm{SAL}-\mathrm{JZL} 8$, $n=$ MOR-VEH 8, $n=$ MOR-JZL 8). Data represent mean values \pm SEM; $* * * p<0.001$ vs SAL-VEH group (Student-Newman-Keuls post hoc test)

and JZL-SAL vs VEH-SAL, Fig. 6a). Likewise, the ratio between phosphorylated and total Akt in the NAc was increased only in rats repeatedly treated with saline followed by acute treatment with JZL184 $(p<0.05$, Mann-Whitney $U$ test for JZL-MOR vs JZL-SAL and $p<0.01$, Mann-Whitney $U$ test for JZL-SAL vs VEH-SAL, Fig. 6b).

CB1 cannabinoid receptor and p-Akt phosphorylation in the prefrontal cortex of rats acutely treated with JZL184 after repeated pretreatment with morphine

Treatment with JZL184 increased the ratio between phosphorylated and total CB1 receptors in the PFC of saline- but not morphine-pretreated rats $(p<0.05$, Mann-Whitney $U$ test for

Amygdala

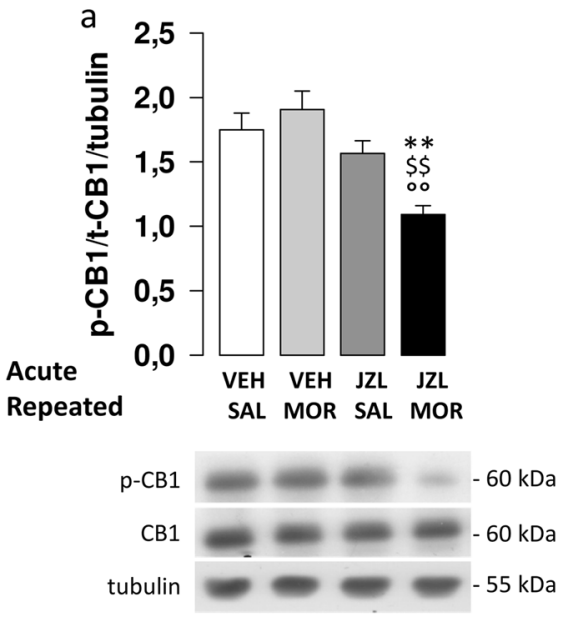

Fig. $5 \mathrm{CB} 1$ cannabinoid receptor and p-Akt phosphorylation in the amygdala of rats repeatedly treated with morphine and acutely treated with JZL184. Animals injected for 5 days with morphine (MOR) and treated acutely with JZL184 (JZL) before testing showed a reduction in the ratio between phosphorylated and total $\mathrm{CB} 1$ receptor protein in the amygdala compared to all the other experimental groups (a). Similarly, in the amygdala of repeatedly morphine-exposed rats treated with JZL184

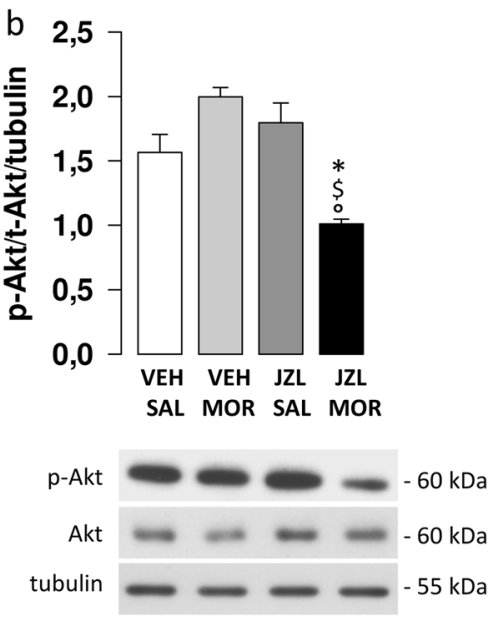

before testing, the ratio between phosphorylated and total Akt protein decreased compared to the other experimental groups (b) ( $n=\mathrm{VEH}-$ SAL 5, $n=$ VEH-MOR 5, $n=$ JZL-SAL $6, n=$ JZL-MOR 5). Data represent mean values \pm SEM; $* p<0.05, * * p<0.01$ vs VEH-SAL group, ${ }^{\circ} p<0.05,{ }^{\circ} p<0.01$ vs VEH-MOR group, $\$ p<0.05, \$ \$ p<0.01$ vs JZLSAL group (Mann-Whitney $U$ test) 


\section{Nucleus Accumbens}

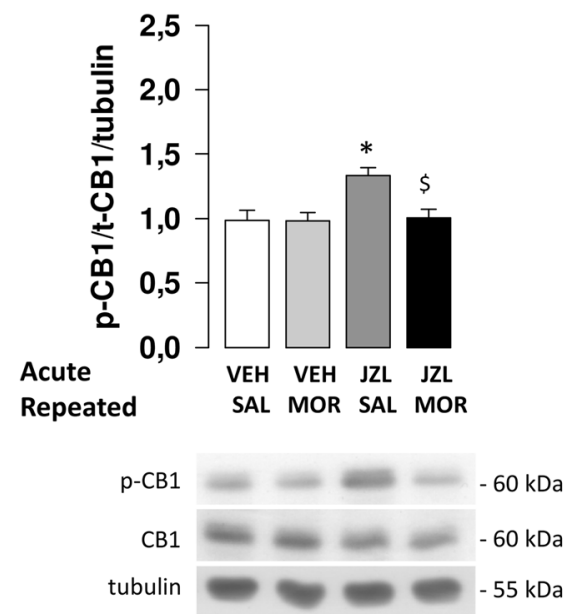

b
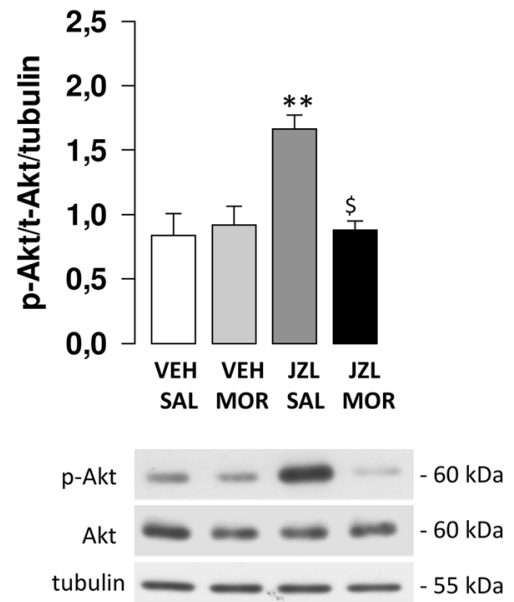

Fig. 6 CB1 cannabinoid receptor and p-Akt phosphorylation in the NAc of rats repeatedly treated with morphine and acutely treated with JZL184. Acute administration of JZL184 (JZL) increased the ratio between phosphorylated and total $\mathrm{CB} 1$ receptors in the NAc, but this effect disappeared when rats acutely treated with JZL184 were repeatedly pretreated with morphine (MOR) (a). Similarly, the ratio between phosphorylated and

JZL-MOR vs JZL-SAL and JZL-SAL vs VEH-SAL Fig. 7a). Similarly, the acute administration of JZL184 increased the ratio between phosphorylated and total Akt protein, but this effect disappeared when rats acutely treated with JZL184 were repeatedly pretreated with morphine $(p<0.05$, MannWhitney $U$ test for JZL-MOR vs JZL-SAL and JZL-SAL vs VEH-SAL Fig. 7b). total Akt protein increased in the NAc of saline- (VEH) but not morphinepretreated rats (b) ( $n=\mathrm{VEH}-\mathrm{SAL} 4, n=\mathrm{VEH}-\mathrm{MOR} 4, n=\mathrm{JZL}-\mathrm{SAL} 4$, $n=\mathrm{JZL}-\mathrm{MOR} 4)$. Data represent mean values $\pm \mathrm{SEM} ; * p<0.05$, $* * p<$ 0.01 vs VEH-SAL group, $\$ p<0.05$ vs JZL-SAL group (Mann-Whitney $U$ test)

\section{Discussion}

In this study, we provide the first evidence for unidirectional cross-tolerance between opioid and endocannabinoid neurotransmission in the modulation of social play behavior. In particular, we found that cross-tolerance to the playenhancing effects of the 2-AG hydrolysis inhibitor JZL184

\section{Prefrontal Cortex}

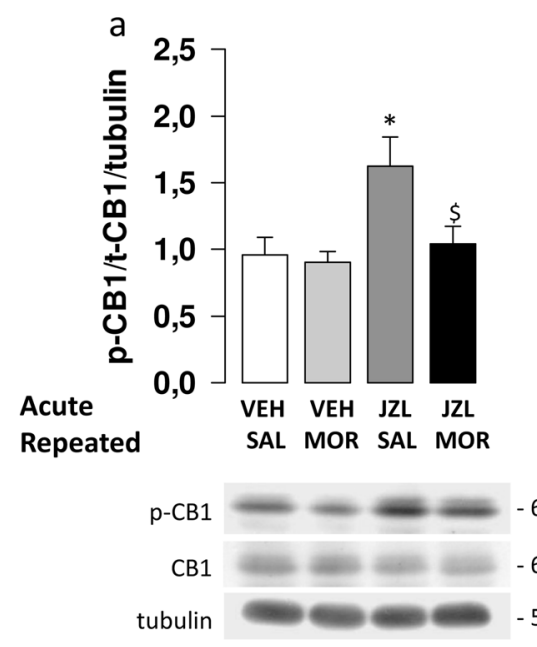

Fig. 7 CB1 cannabinoid receptor and p-Akt phosphorylation in the prefrontal cortex of rats repeatedly exposed to morphine and acutely treated with JZL184. Acute administration of JZL184 (JZL) increased the ratio between phosphorylated and total CB1 receptors in the PFC of saline(VEH) but not morphine- (MOR) pretreated rats (a). Similarly, the ratio
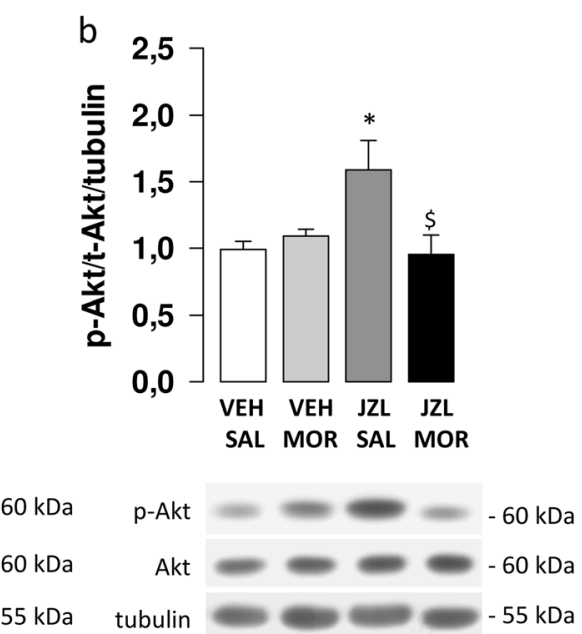

between phosphorylated and total Akt protein increased in the NAc of saline- but not morphine-pretreated rats (b) ( $n=$ VEH-SAL $5, n=$ VEHMOR 5, $n=\mathrm{JZL}-\mathrm{SAL} 5, n=\mathrm{JZL}-\mathrm{MOR} 5$ ). Data represent mean values \pm SEM; $* p<0.05$ vs VEH-SAL group, $\$ p<0.05$, vs JZL-SAL (MannWhitney $U$ test) 
occurred after repeated administration of morphine, accompanied by changes in the phosphorylation, and therefore the activation, of both $\mathrm{CB} 1$ receptors and their effector Akt in the NAc, amygdala and prefrontal cortex.

The endocannabinoid and endogenous opioid systems share similar characteristics. Thus, both opioid and cannabinoid receptors belong to the super-family of seven-transmembrane $G$ protein-coupled receptors, they activate Gi/Go GTP-binding proteins, modulate similar intracellular systems, co-localize in several brain regions and their activation results in similar behavioral outcomes (Fattore et al. 2005, 2010; Gerrits et al. 2003; Maldonado et al. 2011; Manzanares et al. 1999; Parolaro et al. 2010; Pellissier et al. 2018; Volkow et al. 2017; Wenzel and Cheer 2018). A large body of evidence indicates that endocannabinoid and opioid neurotransmission interact to mediate reward processes, including social play reward (Fattore et al. 2005; Manzanares et al. 1999; Parolaro et al. 2007; Trezza et al. 2010; Wei et al. 2017; Wei et al. 2016). For example, it has been shown that the play-enhancing effects of drugs that magnify endocannabinoid activity by interfering with either anandamide or 2-AG degradation are blocked by pretreatment with either cannabinoid or opioid receptor antagonists (Manduca et al. 2016; Solinas and Goldberg 2005; Trezza and Vanderschuren 2008, 2009). This functional interaction is bidirectional, since the play-enhancing effects of opioid receptor agonists are antagonized not only by opioid but also by cannabinoid receptor antagonists (Trezza and Vanderschuren 2008, 2009). More recently, we have shown that endocannabinoid-opioid interaction in social play occurs via the NAc, since the play-enhancing effects induced by systemic administration of the 2-AG hydrolysis inhibitor JZL184 were counteracted by blockade of NAc $\mu$-opioid receptors. Conversely, the increase in social play behavior induced by systemic administration of the opioid receptor agonist morphine was counteracted by intra-NAc administration of the cannabinoid receptor antagonist SR141716A (Manduca et al. 2016).

Studies in laboratory animals have also shown that repeated administration of cannabinoid or opioid drugs induces crosstolerance to their acute behavioral and physiological effects (Maldonado 2002; Robledo et al. 2008). For example, tolerance to the analgesic and hypothermic effects of morphine developed in laboratory animals pre-exposed to cannabinoid agonists, and vice versa (Massi et al. 2001; Smith et al. 1994; Thorat and Bhargava 1994). However, cross-sensitization has also been reported. Thus, rats pre-exposed to cannabinoids showed a heightened locomotor response to opioids (Cadoni et al. 2001; Lamarque et al. 2001; Pontieri et al. 2001a) and vice versa (Pontieri et al. 2001b). Furthermore, morphine-dependent rats showed sensitization to the acute antinociceptive effect of cannabinoids (Rubino et al. 1997; Vigano et al. 2005a), and repeated cannabinoid exposure has been shown to increase opiate selfadministration in rats (Biscaia et al. 2008; Ellgren et al. 2007; Norwood et al. 2003).
Here, we extend this scenario by showing that opioidcannabinoid cross-tolerance exists in social play behavior. Indeed, the play-enhancing effects induced by systemic administration of the 2-AG hydrolysis inhibitor JZL184 were suppressed in animals repeatedly pretreated with morphine, indicating that cross-tolerance to the effects of JZL184 had occurred after repeated administration of morphine.

However, this cross-tolerance was unidirectional. That is, we found that acute administration of morphine before testing markedly increased social play in rats pretreated with both JZL184 and vehicle, indicating that tolerance to the playenhancing effects of morphine had not occurred after repeated treatment with the indirect cannabinoid agonist. A possible explanation for this negative finding is that JZL184 is not a cannabinoid receptor agonist. Rather, it acts as indirect agonist by enhancing local 2-AG signaling through the inhibition of its hydrolysis (Long et al. 2009). Since endocannabinoids are released on demand (Alger and Kim 2011; Di Marzo 2006; Piomelli 2003), i.e., only when appropriate stimuli mobilize them, it is possible that a direct, impulse-independent activation of $\mathrm{CB} 1$ receptors is needed to induce cross-tolerance to the play-enhancing effects of morphine. In support of this possibility, it has been shown that the development of tolerance to the effects of endocannabinoids involves different mechanisms than those implicated in tolerance to direct cannabinoid agonists. For instance, anandamide-tolerant mice did not show cross-tolerance to the antinociceptive responses induced by mu-, delta-, or kappa-opioid agonists, while THCtolerant mice exhibited cross-tolerance to opioid agonists (Welch 1997). However, it is still unknown whether the same holds true for 2-AG, or not. To address this issue, we performed an additional experiment in which we tested whether the play-enhancing effects of morphine were maintained, or not, when rats were repeatedly pretreated with the CB1 cannabinoid receptor agonist WIN55,212-2. We found that acute administration of morphine before testing markedly increased social play in rats pretreated with either WIN or its vehicle, indicating that regardless how the endocannabinoid system is repeatedly activated (i.e., indirectly by inhibiting the hydrolysis of 2-AG or directly by WIN binding to cannabinoid receptors), the opioid-cannabinoid cross-tolerance in the modulation of social play behavior remains unidirectional.

As for the mechanisms underlying the development of morphine-induced tolerance to the play-enhancing effects of JZL184, it has been reported that chronic exposure to opiates results in alterations of cannabinoid receptor density and/or signal transduction (Gonzalez et al. 2002; Romero et al. 1998; Rubino et al. 1997; Shapira et al. 1998). To test the possibility that the development of tolerance to the playenhancing effects of JZL184 in animals pretreated with morphine is due to opioid-induced changes in cannabinoid receptor expression or activity, we measured the phosphorylation of the $\mathrm{CB} 1$ receptor and its effector Akt in the amygdala, NAc 
and prefrontal cortex, key brain regions implicated in social play behavior (Manduca et al. 2016; Trezza et al. 2012; van Kerkhof et al. 2013; Vanderschuren et al. 2016). Since CB1 receptor activation by endogenous and/or exogenous cannabinoids leads to the induction of signaling cascades culminating in Akt activation, the evaluation of Akt phosphorylation is useful to assess CB1 receptor activation (Gomez del Pulgar et al. 2000). It is generally accepted that the phosphorylation of the carboxy terminus of the CB1 cannabinoid receptor induces the internalization of the agonist-activated full-length receptor (Daigle et al. 2008; Garcia et al. 1998; Martin et al. 2000; Nogueras-Ortiz and Yudowski 2016; Rubino et al. 2005). For this reason, increased CB1 receptor phosphorylation reflects the compensatory response to reduce $\mathrm{CB} 1$ receptor-mediated signaling after endocannabinoid system activation, and can be used as an indirect parameter to evaluate CB1 receptor activation, as already described (Servadio et al. 2016; Trezza et al. 2012). We found that acute administration of JZL184 increased the phosphorylation, and therefore the activation, of both CB1 receptors and their effector Akt in the NAc and prefrontal cortex. This is in line with previous studies showing that 2-AG signaling in the NAc (Manduca et al. 2016; Wei et al. 2016) and prefrontal cortex (Gould et al. 2012; Robinson et al. 2010) is involved in social (play) behavior. Interestingly, however, we found that the JZL-induced increase in CB1 and Akt phosphorylation in both the NAc and prefrontal cortex disappeared when JZL-treated rats were pretreated with morphine. Furthermore, we found that only animals repeatedly treated with morphine and acutely administered with JZL184 before testing showed a reduced phosphorylation of both $\mathrm{CB} 1$ receptors and Akt in the amygdala.

Several mechanisms have been hypothesized to explain the existence of opioid/cannabinoid cross-tolerance, ranging from modifications in receptor expression to alterations in receptor signaling. In our experimental conditions, it seems unlikely that pretreatment with morphine altered cannabinoid receptor expression, since the total amount of $\mathrm{CB} 1$ receptor did not differ among the experimental groups. On the other hand, the endogenous opioid system may interfere with endocannabinoid neurotransmission by affecting its signaling pathway. For instance, chronic morphine exposure may impact $\mathrm{CB} 1$ activity by decreasing the level of $\mathrm{G}$ protein activation (Gonzalez et al. 2002; Welch 1997). Additionally, longterm exposure to opioid receptor agonists induces CB1 desensitization through inhibition of cAMP production, since both opioid and endocannabinoid signaling pathways converge at the level of adenylyl cyclase (Vigano et al. 2005a, b). Another explanation is that the functional interaction between opioid and cannabinoid drugs is due to alterations of their endogenous tone. To support this possibility, it has been shown that, in addition to alterations in $\mathrm{CB} 1$ receptor function in the NAc, chronic morphine exposure strongly lowered 2-AG content in several brain regions, including the NAc and amygdala, without significant changes in anandamide levels (Vigano et al. 2003). On this basis, it is still possible that the playenhancing effects of JZL184 disappear as a consequence of reduced 2-AG levels induced by repeated treatment with morphine.

In conclusion, we provide new evidence that the endogenous opioid and the endocannabinoid systems interact in the modulation of social play. In particular, unidirectional heterologous cross-tolerance exists to the effects of the 2-AG hydrolysis inhibitor JZL184 on social play in animals repeatedly pretreated with the opioid agonist morphine. Our results indicate that the mechanism involved in such interactions could take place at the cannabinoid receptor level, although the changes in the downstream events associated or a common release of several neurotransmitters cannot be excluded. A better understanding of opioid-cannabinoid interactions in social play can contribute to clarify neurobiological aspects of social behavior at young age and may provide new therapeutic targets for social dysfunctions.

Funding This work was supported by 7th Framework Program People (Marie Curie Career Reintegration Grant PCIG09-GA-2011-293589 to V.T.) and Jerome Lejeune Foundation (grant no. 1674 to V.T.). This work was partially supported by Excellence Departments, MIUR-Italy, Grant/ Award Numbers: ARTICOLO 1, COMMI 314- 337 LEGGE 232/2016, ARTICOLO 1.

\section{Compliance with ethical standards}

Conflict of interest The authors declare that, except for income received from their primary employers, no financial support or compensation has been received from any individual or corporate entity over the past 5 years for research or professional service, and there are no personal financial holdings that could be perceived as constituting a potential conflict of interest.

\section{References}

Alger BE, Kim J (2011) Supply and demand for endocannabinoids. Trends Neurosci 34:304-315

Befort K (2015) Interactions of the opioid and cannabinoid systems in reward: insights from knockout studies. Front Pharmacol 6:6

Biscaia M, Fernandez B, Higuera-Matas A, Miguens M, Viveros MP, Garcia-Lecumberri C, Ambrosio E (2008) Sex-dependent effects of periadolescent exposure to the cannabinoid agonist CP-55,940 on morphine self-administration behaviour and the endogenous opioid system. Neuropharmacology 54:863-873

Bouaboula M, Bourrie B, Rinaldi-Carmona M, Shire D, Le Fur G, Casellas P (1995) Stimulation of cannabinoid receptor CB1 induces krox-24 expression in human astrocytoma cells. J Biol Chem 270: 13973-13980

Cadoni C, Pisanu A, Solinas M, Acquas E, Di Chiara G (2001) Behavioural sensitization after repeated exposure to Delta 9tetrahydrocannabinol and cross-sensitization with morphine. Psychopharmacology 158:259-266

Daigle TL, Kwok ML, Mackie K (2008) Regulation of CB1 cannabinoid receptor internalization by a promiscuous phosphorylationdependent mechanism. J Neurochem 106:70-82 
Di Marzo V (2006) A brief history of cannabinoid and endocannabinoid pharmacology as inspired by the work of British scientists. Trends Pharmacol Sci 27:134-140

Di Marzo V, Bifulco M, De Petrocellis L (2004) The endocannabinoid system and its therapeutic exploitation. Nat Rev Drug Discov 3: 771-784

Ellgren M, Spano SM, Hurd YL (2007) Adolescent cannabis exposure alters opiate intake and opioid limbic neuronal populations in adult rats. Neuropsychopharmacology 32:607-615

Erbs E, Faget L, Scherrer G, Matifas A, Filliol D, Vonesch JL, Koch M, Kessler P, Hentsch D, Birling MC, Koutsourakis M, Vasseur L, Veinante P, Kieffer BL, Massotte D (2015) A mu-delta opioid receptor brain atlas reveals neuronal co-occurrence in subcortical networks. Brain Struct Funct 220:677-702

Fattore L, Deiana S, Spano SM, Cossu G, Fadda P, Scherma M, Fratta W (2005) Endocannabinoid system and opioid addiction: behavioural aspects. Pharmacol Biochem Behav 81:343-359

Fattore L, Melis M, Fadda P, Pistis M, Fratta W (2010) The endocannabinoid system and nondrug rewarding behaviours. Exp Neurol 224:23-36

Filizola M, Devi LA (2013) Grand opening of structure-guided design for novel opioids. Trends Pharmacol Sci 34:6-12

Fowler CJ (2012) Monoacylglycerol lipase - a target for drug development? Br J Pharmacol 166:1568-1585

Garcia DE, Brown S, Hille B, Mackie K (1998) Protein kinase C disrupts cannabinoid actions by phosphorylation of the CB1 cannabinoid receptor. J Neurosci 18:2834-2841

Gerrits MA, Lesscher HB, van Ree JM (2003) Drug dependence and the endogenous opioid system. European neuropsychopharmacology 13:424-434

Gomez del Pulgar T, Velasco G, Guzman M (2000) The CB1 cannabinoid receptor is coupled to the activation of protein kinase $\mathrm{B} / \mathrm{Akt}$. Biochem J 347:369-373

Gonzalez S, Fernandez-Ruiz J, Sparpaglione V, Parolaro D, Ramos JA (2002) Chronic exposure to morphine, cocaine or ethanol in rats produced different effects in brain cannabinoid $\mathrm{CB}(1)$ receptor binding and mRNA levels. Drug Alcohol Depend 66:77-84

Gould GG, Seillier A, Weiss G, Giuffrida A, Burke TF, Hensler JG, Rock C, Tristan A, McMahon LR, Salazar A, O'Connor JC, Satsangi N, Satsangi RK, Gu TT, Treat K, Smolik C, Schultz ST (2012) Acetaminophen differentially enhances social behavior and cortical cannabinoid levels in inbred mice. Prog Neuro-Psychopharmacol Biol Psychiatry 38:260-269

Gray JM, Vecchiarelli HA, Morena M, Lee TT, Hermanson DJ, Kim AB, McLaughlin RJ, Hassan KI, Kuhne C, Wotjak CT, Deussing JM, Patel S, Hill MN (2015) Corticotropin-releasing hormone drives anandamide hydrolysis in the amygdala to promote anxiety. J Neurosci 35:3879-3892

Hill MN, Karatsoreos IN, Hillard CJ, McEwen BS (2010) Rapid elevations in limbic endocannabinoid content by glucocorticoid hormones in vivo. Psychoneuroendocrinology 35:1333-1338

Kieffer BL (1995) Recent advances in molecular recognition and signal transduction of active peptides: receptors for opioid peptides. Cell Mol Neurobiol 15:615-635

Kilkenny C, Browne WJ, Cuthill IC, Emerson M, Altman DG (2010) Improving bioscience research reporting: the ARRIVE guidelines for reporting animal research. PLoS Biol 8:e1000412

Koob GF, Volkow ND (2010) Neurocircuitry of addiction. Neuropsychopharmacology 35:217-238

Lamarque S, Taghzouti K, Simon H (2001) Chronic treatment with $\operatorname{Delta}(9)$-tetrahydrocannabinol enhances the locomotor response to amphetamine and heroin. Implications for vulnerability to drug addiction. Neuropharmacology 41:118-129

Le Merrer J, Becker JA, Befort K, Kieffer BL (2009) Reward processing by the opioid system in the brain. Physiol Rev 89:1379-1412
Long JZ, Li W, Booker L, Burston JJ, Kinsey SG, Schlosburg JE, Pavon FJ, Serrano AM, Selley DE, Parsons LH, Lichtman AH, Cravatt BF (2009) Selective blockade of 2-arachidonoylglycerol hydrolysis produces cannabinoid behavioral effects. Nat Chem Biol 5:37-44

Lowry OH, Rosebrough NJ, Farr AL, Randall RJ (1951) Protein measurement with the Folin phenol reagent. J Biol Chem 193:265-275

Maldonado R (2002) Study of cannabinoid dependence in animals. Pharmacol Ther 95:153-164

Maldonado R, Berrendero F, Ozaita A, Robledo P (2011) Neurochemical basis of cannabis addiction. Neuroscience 181:1-17

Manduca A, Lassalle O, Sepers M, Campolongo P, Cuomo V, Marsicano G, Kieffer B, Vanderschuren LJ, Trezza V, Manzoni OJ (2016) Interacting cannabinoid and opioid receptors in the nucleus accumbens core control adolescent social play. Front Behav Neurosci 10: 211

Manzanares J, Corchero J, Romero J, Fernandez-Ruiz JJ, Ramos JA, Fuentes JA (1999) Pharmacological and biochemical interactions between opioids and cannabinoids. Trends Pharmacol Sci 20:287294

Martin M, Ledent C, Parmentier M, Maldonado R, Valverde O (2000) Cocaine, but not morphine, induces conditioned place preference and sensitization to locomotor responses in CB1 knockout mice. Eur J Neurosci 12:4038-4046

Massi P, Vaccani A, Romorini S, Parolaro D (2001) Comparative characterization in the rat of the interaction between cannabinoids and opiates for their immunosuppressive and analgesic effects. J Neuroimmunol 117:116-124

McCutcheon JE, Marinelli M (2009) Age matters. Eur J Neurosci 29: 997-1014

Mechoulam R, Hanus LO, Pertwee R, Howlett AC (2014) Early phytocannabinoid chemistry to endocannabinoids and beyond. Nat Rev Neurosci 15:757-764

Niesink RJ, van Ree JM (1982) Short-term isolation increases social interactions of male rats: a parametric analysis. Physiol Behav 29: $819-825$

Nogueras-Ortiz C, Yudowski GA (2016) The multiple waves of cannabinoid 1 receptor signaling. Mol Pharmacol 90:620-626

Norwood CS, Cornish JL, Mallet PE, McGregor IS (2003) Pre-exposure to the cannabinoid receptor agonist CP 55940 enhances morphine behavioral sensitization and alters morphine self-administration in Lewis rats. Eur J Pharmacol 465:105-114

Ozaita A, Puighermanal E, Maldonado R (2007) Regulation of PI3K/Akt/ GSK-3 pathway by cannabinoids in the brain. J Neurochem 102: $1105-1114$

Panksepp J (1981) The ontogeny of play in rats. Dev Psychobiol 14:327_ 332

Panksepp J, Beatty WW (1980) Social deprivation and play in rats. Behavioral and neural biology 30:197-206

Parolaro D, Vigano D, Realini N, Rubino T (2007) Role of endocannabinoids in regulating drug dependence. Neuropsychiatr Dis Treat 3:711-721

Parolaro D, Rubino T, Vigano D, Massi P, Guidali C, Realini N (2010) Cellular mechanisms underlying the interaction between cannabinoid and opioid system. Curr Drug Targets 11:393-405

Pellis SM, Pellis VC (1987) Play-fighting differs from serious fighting in both target of attack and tactics of fighting in the laboratory rat Rattus norvegicus. Aggress Behav 13:227-242

Pellissier LP, Gandia J, Laboute T, Becker JAJ, Le Merrer J (2018) mu opioid receptor, social behaviour and autism spectrum disorder: reward matters. Br J Pharmacol 175:2750-2769

Piomelli D (2003) The molecular logic of endocannabinoid signalling. Nat Rev Neurosci 4:873-884

Pontieri FE, Monnazzi P, Scontrini A, Buttarelli FR, Patacchioli FR (2001a) Behavioral sensitization to heroin by cannabinoid pretreatment in the rat. Eur J Pharmacol 421:R1-R3 
Pontieri FE, Monnazzi P, Scontrini A, Buttarelli FR, Patacchioli FR (2001b) Behavioral sensitization to WIN55212.2 in rats pretreated with heroin. Brain Res 898:178-180

Robinson SA, Loiacono RE, Christopoulos A, Sexton PM, Malone DT (2010) The effect of social isolation on rat brain expression of genes associated with endocannabinoid signaling. Brain Res 1343:153167

Robledo P, Berrendero F, Ozaita A, Maldonado R (2008) Advances in the field of cannabinoid-opioid cross-talk. Addict Biol 13:213-224

Romero J, Fernandez-Ruiz JJ, Vela G, Ruiz-Gayo M, Fuentes JA, Ramos JA (1998) Autoradiographic analysis of cannabinoid receptor binding and cannabinoid agonist-stimulated [35S]GTP gamma S binding in morphine-dependent mice. Drug Alcohol Depend 50:241249

Rubino T, Tizzoni L, Vigano D, Massi P, Parolaro D (1997) Modulation of rat brain cannabinoid receptors after chronic morphine treatment. Neuroreport 8:3219-3223

Rubino T, Forlani G, Vigano D, Zippel R, Parolaro D (2005) Ras/ERK signalling in cannabinoid tolerance: from behaviour to cellular aspects. J Neurochem 93:984-991

Schneider M, Koch M (2005) Deficient social and play behavior in juvenile and adult rats after neonatal cortical lesion: effects of chronic pubertal cannabinoid treatment. Neuropsychopharmacology 30: 944-957

Segatto M, Manduca A, Lecis C, Rosso P, Jozwiak A, Swiezewska E, Moreno S, Trezza V, Pallottini V (2014) Simvastatin treatment highlights a new role for the isoprenoid/cholesterol biosynthetic pathway in the modulation of emotional reactivity and cognitive performance in rats. Neuropsychopharmacology 39:841-854

Servadio M, Melancia F, Manduca A, di Masi A, Schiavi S, Cartocci V, Pallottini V, Campolongo P, Ascenzi P, Trezza V (2016) Targeting anandamide metabolism rescues core and associated autistic-like symptoms in rats prenatally exposed to valproic acid. Transl Psychiatry 6:e902

Shapira M, Gafni M, Sarne Y (1998) Independence of, and interactions between, cannabinoid and opioid signal transduction pathways in N18TG2 cells. Brain Res 806:26-35

Shapiro SS, Wilk MB (1965) An analysis of variance test for normality (complete samples). Biometrika 52:591-611

Siviy SM, Panksepp J (2011) In search of the neurobiological substrates for social playfulness in mammalian brains. Neurosci Biobehav Rev 35:1821-1830

Smith PB, Welch SP, Martin BR (1994) Interactions between delta 9tetrahydrocannabinol and kappa opioids in mice. J Pharmacol Exp Ther 268:1381-1387

Solinas M, Goldberg SR (2005) Motivational effects of cannabinoids and opioids on food reinforcement depend on simultaneous activation of cannabinoid and opioid systems. Neuropsychopharmacology 30: 2035-2045

Spear LP (2000) The adolescent brain and age-related behavioral manifestations. Neurosci Biobehav Rev 24:417-463

Thorat SN, Bhargava HN (1994) Evidence for a bidirectional crosstolerance between morphine and delta 9-tetrahydrocannabinol in mice. Eur J Pharmacol 260:5-13

Trezza V, Vanderschuren LJ (2008) Bidirectional cannabinoid modulation of social behavior in adolescent rats. Psychopharmacology 197: 217-227

Trezza V, Vanderschuren LJ (2009) Divergent effects of anandamide transporter inhibitors with different target selectivity on social play behavior in adolescent rats. J Pharmacol Exp Ther 328:343-350

Trezza V, Baarendse PJ, Vanderschuren LJ (2010) The pleasures of play: pharmacological insights into social reward mechanisms. Trends Pharmacol Sci 31:463-469
Trezza V, Damsteegt R, Achterberg EJ, Vanderschuren LJ (2011a) Nucleus accumbens mu-opioid receptors mediate social reward. J Neurosci 31:6362-6370

Trezza V, Campolongo P, Vanderschuren LJ (2011b) Evaluating the rewarding nature of social interactions in laboratory animals. Dev Cogn Neurosci 1:444-458

Trezza V, Damsteegt R, Manduca A, Petrosino S, Van Kerkhof LW, Pasterkamp RJ, Zhou Y, Campolongo P, Cuomo V, Di Marzo V, Vanderschuren LJ (2012) Endocannabinoids in amygdala and nucleus accumbens mediate social play reward in adolescent rats. J Neurosci 32:14899-14908

van Kerkhof LW, Damsteegt R, Trezza V, Voorn P, Vanderschuren LJ (2013) Social play behavior in adolescent rats is mediated by functional activity in medial prefrontal cortex and striatum. Neuropsychopharmacology 38:1899-1909

Vanderschuren LJ, Stein EA, Wiegant VM, Van Ree JM (1995a) Social play alters regional brain opioid receptor binding in juvenile rats. Brain Res 680:148-156

Vanderschuren LJ, Niesink RJ, Spruijt BM, Van Ree JM (1995b) Mu- and kappa-opioid receptor-mediated opioid effects on social play in juvenile rats. Eur J Pharmacol 276:257-266

Vanderschuren LJ, Niesink RJ, Van Ree JM (1997) The neurobiology of social play behavior in rats. Neurosci Biobehav Rev 21:309-326

Vanderschuren LJ, Achterberg EJ, Trezza V (2016) The neurobiology of social play and its rewarding value in rats. Neurosci Biobehav Rev 70:86-105

Vigano D, Grazia Cascio M, Rubino T, Fezza F, Vaccani A, Di Marzo V, Parolaro D (2003) Chronic morphine modulates the contents of the endocannabinoid, 2-arachidonoyl glycerol, in rat brain. Neuropsychopharmacology 28:1160-1167

Vigano D, Rubino T, Vaccani A, Bianchessi S, Marmorato P, Castiglioni C, Parolaro D (2005a) Molecular mechanisms involved in the asymmetric interaction between cannabinoid and opioid systems. Psychopharmacology 182:527-536

Vigano D, Rubino T, Parolaro D (2005b) Molecular and cellular basis of cannabinoid and opioid interactions. Pharmacol Biochem Behav 81: 360-368

Volkow ND, Hampson AJ, Baler RD (2017) Don't worry, be happy: endocannabinoids and cannabis at the intersection of stress and reward. Annu Rev Pharmacol Toxicol 57:285-308

Wartmann M, Campbell D, Subramanian A, Burstein SH, Davis RJ (1995) The MAP kinase signal transduction pathway is activated by the endogenous cannabinoid anandamide. FEBS Lett 359:133136

Wei D, Lee D, Li D, Daglian J, Jung KM, Piomelli D (2016) A role for the endocannabinoid 2-arachidonoyl-sn-glycerol for social and high-fat food reward in male mice. Psychopharmacology 233:1911-1919

Wei D, Allsop S, Tye K, Piomelli D (2017) Endocannabinoid signaling in the control of social behavior. Trends Neurosci 40:385-396

Welch SP (1997) Characterization of anandamide-induced tolerance: comparison to delta 9-THC-induced interactions with dynorphinergic systems. Drug Alcohol Depend 45:39-45

Wenzel JM, Cheer JF (2018) Endocannabinoid regulation of reward and reinforcement through interaction with dopamine and endogenous opioid signaling. Neuropsychopharmacology 43:103-115

Publisher's note Springer Nature remains neutral with regard to jurisdictional claims in published maps and institutional affiliations. 